\title{
Sorafenib treatment for papillary thyroid carcinoma with diffuse lung metastases in a child with autism spectrum disorder: a case report
}

Yousuke Higuchi ${ }^{1}$, Takayuki Motoki ${ }^{2}$, Hisashi Ishida ${ }^{1}$, Kiichiro Kanamitsu' ${ }^{1}$, Kana Washio', Takanori Oyama ${ }^{3}$, Takuo Noda ${ }^{3}$, Yasuko Tsurumaru', Ayumi Okada ${ }^{4}$, Hirokazu Tsukahara ${ }^{4}$ and Akira Shimada ${ }^{1 *}$

\begin{abstract}
Background: Pediatric papillary thyroid carcinoma frequently presents with lymph node involvement and distant metastases. Sorafenib, an oral multikinase inhibitor, has been used to treat radioactive iodine (RAl) therapy-refractory thyroid carcinoma in adults; however, pediatric experience is limited. Medical procedures and hospitalization for children with autism spectrum disorder may be challenging.

Case presentation: An 11-year-old boy with autism spectrum disorder and moderate intellectual impairment presented with dyspnea on exertion with thyroid carcinoma and diffuses lung metastases. Total thyroidectomy and adjuvant RAI therapy is the standard treatment; however, the latter therapy was impractical because of his respiratory status and challenging behaviors. He was therefore started on sorafenib $200 \mathrm{mg} /$ day $\left(150 \mathrm{mg} / \mathrm{m}^{2} /\right.$ day $)$ and this dosage was increased to $400 \mathrm{mg} /$ day $\left(300 \mathrm{mg} / \mathrm{m}^{2} /\right.$ day). The adverse effects were mild and tolerable. After administration of medication, his dyspnea improved and surgery was performed. We attempted to administer RAl therapy after surgery; however, we abandoned it because he had difficulty taking care of himself according to isolation room rules. Thyrotropin suppression therapy was therefore started and sorafenib treatment ( $400 \mathrm{mg} /$ day) resumed. Follow-up imaging showed regression of pulmonary metastases. The metastases have remained stable for over 24 months on continuous sorafenib treatment without serious adverse events.
\end{abstract}

Conclusion: We inevitably used sorafenib as an alternative to standard therapy because of the patient's specific circumstances. Individualized strategies for pediatric cancer patients with autism spectrum disorder are needed.

Keywords: Sorafenib, Pediatrics, Papillary thyroid carcinoma, Lung metastases, Autism spectrum disorder

\section{Background}

Thyroid carcinoma is rare in the pediatric population and its incidence in the United States in 2010-2014 was 0.4 per 100,000 in 10-14-year-old male individuals [1]. Papillary thyroid carcinoma (PTC) is the most common thyroid malignancy. Although PTC is usually indolent, pediatric patients with PTC frequently present with distant metastases [2]. Even though cervical lymph node involvement and pulmonary metastases are common, the

\footnotetext{
* Correspondence: pajj236e@okayama-u.ac.jp

'Department of Pediatrics, Okayama University Hospital, 2-5-1 Shikata-cho,

Kita-ku, Okayama 700-8558, Japan

Full list of author information is available at the end of the article
}

prognosis is excellent $[2,3]$. This positive prognosis is considered a result of good response to radioactive iodine (RAI) therapy in pediatric patients with PTC and pulmonary metastases $[4,5]$.

Aberrant activation of mitogen-activated protein kinase signaling pathways is critical for thyroid carcinoma [6]. BRAF (especially V600E), RAS point mutations and RET/ $P T C$ rearrangements are common genetic abnormalities in PTC. Sorafenib, an oral multikinase inhibitor that inhibits BRAF, CRAF, VEGF receptors 1 to 3 , plateletderived growth factor receptors, and RET, is approved by the United States Food and Drug Administration for adults with RAI therapy refractory well-differentiated 
thyroid carcinoma [7, 8]. However, the safety and effectiveness of sorafenib in pediatric patients have not been established. In Japan, sorafenib was approved for unresectable thyroid cancer without age regulation, but there was no experience of using sorafenib in pediatric patients.

Autism spectrum disorder (ASD) is neurodevelopmental impairments of communication, socialization and repetitive behaviors, and frequently co-occur with intellectual disability [9]. The prevalence of ASD is approximately 1 in 68 8-years-old children [10]. Children with ASD tend to engage in their routines and are resistant to change. Therefore, medical procedures and hospitalization for children with ASD may provoke challenging behaviors [11].

Here we report a child with ASD who developed PTC with diffuse lung metastases and was treated with sorafenib.

\section{Case presentation}

An 11-year-old boy with ASD and moderate intellectual disability was taken to regional hospital because of dyspnea on exertion. The breath sounds were diminished, percutaneous oxygen saturation $\left(\mathrm{SpO}_{2}\right)$ was $89 \%$ and $97 \%$ on $5 \mathrm{~L} / \mathrm{min}$ of oxygen. A chest radiograph showed diffuse pulmonary nodules and tracheal deviation to the right (Fig. 1a). A computed tomography scan of the chest and neck revealed innumerable small nodules throughout both lungs (Fig. 2a), a 2-cm nodule in the left thyroid lobe, and enlarged cervical lymph nodes. He was referred to our department for further examination and treatment. His parents were not consanguineous and there was no history of radiation exposure or family history of cancer. Laboratory data showed markedly increased serum thyroglobulin $(\mathrm{Tg})$ concentrations $(2206 \mu \mathrm{g} / \mathrm{L}$, normal range: $0.0-32.7 \mu \mathrm{g} / \mathrm{L})$ with negative $\mathrm{Tg}$ autoantibody $(<6.1 \mathrm{kU} / \mathrm{L}$, normal range: $<13.6 \mathrm{kU} / \mathrm{L}$ ). Fine-needle aspiration cytology of the thyroid nodule confirmed malignancy.

Total thyroidectomy and adjuvant RAI therapy is the standard treatment for such patients; however, these therapies were considered impracticable immediately because of his respiratory status and challenging behaviors (he frequently pulled his oxygen mask off and ran out of the room; therefore, he needed an attendant full time). Even though the safety and effectiveness of sorafenib in children have not been established, our medical team including pediatricians, pediatric surgeons, endocrine surgeons and radiologists discussed potential risks and benefits with his family. After obtaining written informed consent, we decided to prescribe sorafenib. Treatment was started at $200 \mathrm{mg}\left(150 \mathrm{mg} / \mathrm{m}^{2} /\right.$ day $)$ in two divided doses per day (BID) and increased to $400 \mathrm{mg}\left(300 \mathrm{mg} / \mathrm{m}^{2} /\right.$ day) BID because his Tg concentration increased to $3600 \mu \mathrm{g} / \mathrm{L}$. The dose was decided based on a Children's Oncology Group phase 1 study of sorafenib in children with refractory solid tumors and leukemia [12]. We performed physical examination including blood pressure measurement and weekly laboratory examination including serum proteins, bilirubin, aminotransferase, amylase, creatinine, electrolytes, and complete blood counts to evaluate the toxicity of sorafenib. An ordinary moisturizing cream was provided for skin care to prevent a hand-foot skin reaction [13]. The adverse effects of increased aminotransferase concentration (Common Terminology Criteria for Adverse Events [CTCAE] version 4.0, Grade 1), mild diarrhea (CTCAE Grade 1), and hand rash (CTCAE Grade 1) occurred [14]. After 2 months of receiving sorafenib, his dyspnea on exertion had improved and chest radiograph showed relief of tracheal deviation (Fig. 1b). Meanwhile, $\mathrm{Tg}$ concentrations had remained within the range of 1500 $2000 \mu \mathrm{g} / \mathrm{L}$. Then, total thyroidectomy and lymph node dissection were performed 1 week after cessation of sorafenib. The left lobe was excised as completely as possible, with tumor invasion to trachea preventing total excision. The left swollen deep lateral cervical lymph nodes were dissected but superior internal jugular lymph nodes were left in situ because of adhesions to the vagus nerve. His postoperative course was uneventful and there were no surgery-related complications.

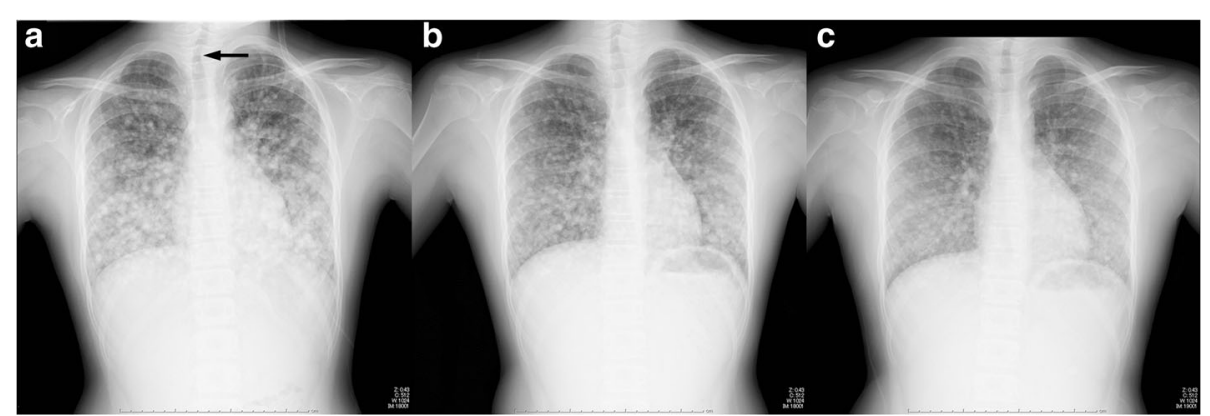

Fig. 1 Chest radiographs. a Chest radiograph showing innumerable lung nodules in a miliary pattern. The trachea is deviated to the right (arrow). b In 2 months after receiving sorafenib and before surgery showing the relief of deviated trachea. $\mathbf{c} \ln 2$ month after surgery and resume sorafenib showing improvement in the lung nodules 


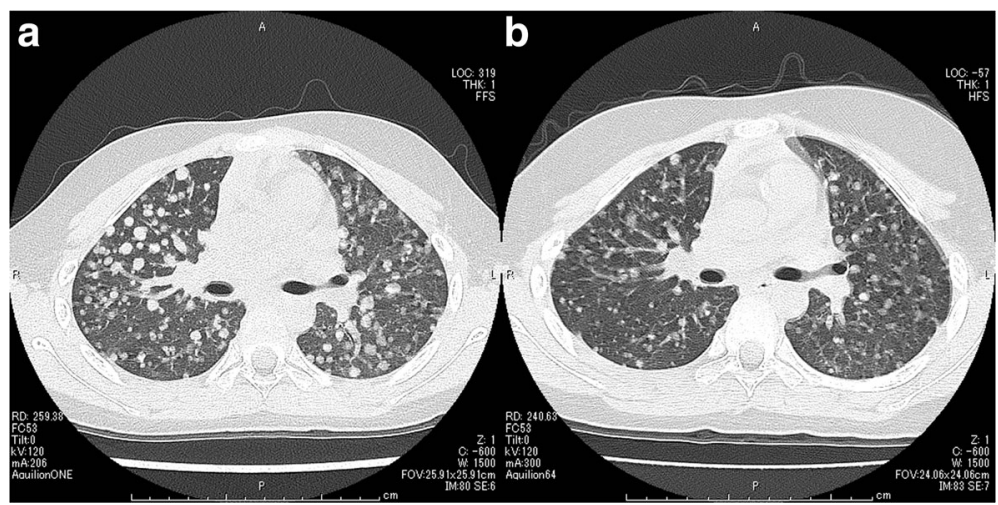

Fig. 2 Radiographic changes in lung metastases. a Chest computed tomography scan showing innumerable metastases. b In 2 month after surgery and resume sorafenib showing regression of lung metastases

Histopathologic examination of the resected specimen revealed PTC of mixed unencapsulated follicular variant pattern, Stage $\mathrm{T} 4_{\mathrm{a}}, \mathrm{N1}_{\mathrm{b}}$, M1 (American Joint Committee on Cancer Staging Manual 7th edition) with positive surgical margins [15].

An RAI whole body scan showed uptake in the thyroid remnant and lungs. We attempted to administer RAI therapy; however, abandoned it eventually because he had difficulty taking care of himself according to isolation room rules (e.g. drink $1.5 \mathrm{~L}$ of water per day, change clothes, and excrete in a designated area) because of his inflexible character and intellectual disability (TanakaBinet Intelligence quotient test showed his mental age was 5 years). Thyrotropin suppression therapy was therefore started and sorafenib treatment (400 mg BID) resumed. Two months after surgery, he was able to ambulate with oxygen at $1 \mathrm{~L} / \mathrm{min}$. Follow-up imaging revealed regression of pulmonary metastases (Fig. $1 \mathrm{c}$ and $2 \mathrm{~b}$ ). The metastases have remained stable for over 24 months on consecutive sorafenib treatment (400 mg BID) without serious adverse event including growth plate widening at his wrists and knees (his bone age was 14 years and consistent with chronological age). Tg concentrations declined to around $400 \mu \mathrm{g} / \mathrm{L}$ and have also remained stable for over 24 months. After receiving informed consent from the patient's parents and with the approval of the Ethics Committee of Okayama University Hospital, we conducted genetic analysis. No common mutations seen in PTC were identified in BRAF, HRAS or KRAS.

\section{Discussion and conclusions}

The American Thyroid Association guidelines Task Force on Pediatric Thyroid Cancer proposes the following management for patients with known distant metastases: monitoring of $\mathrm{Tg}$ on thyrotropin suppression therapy and performing an RAI whole body scan if $\mathrm{Tg}$ concentrations increase [16]. If RAI uptake is confirmed, the patient is treated with RAI therapy. Most children with pulmonary metastases have micronodular disease, which typically has excellent RAI uptake. Therefore, we thought that RAI therapy was needed and attempted to administer it after surgery; however, we were not sure if the patient could receive RAI therapy at that time because of his challenging behaviors. We considered that the significance of total thyroidectomy alone was limited. Therefore, we administered sorafenib expecting of his lung metastases that would allow enough time to train him to receive RAI therapy. Although our nurses, paramedical staff, and his family worked diligently over an extended period time to train him, he remained unable to obey isolation room rules. This, unfortunately, prevented us from administering RAI therapy. Children with ASD have more anxiety and behavioral conduct problems than children without ASD, and challenging behaviors including non-compliance complicate the treatment [13]. Developing individual approach is important for the management of children with ASD presenting with fatal disease such as cancer.

There are several subtypes of PTC; the follicular variant of PTC has a follicular architectural pattern and nuclear features similar to those of classical PTC. Patients with follicular variant of PTC and extrathyroidal extension of their tumor or distant metastases have a higher disease-specific mortality than those with classical PTC [17]. Our patient also had infiltrative tumor and miliary pulmonary metastases. We identified no somatic mutations in BRAF, HRAS, or KRAS in our patient. However, NRAS and chromosomal rearrangements were not included in our sequence analysis. Some recent reports have used next-generation sequencing to investigate both conventional and rare mutations and chromosomal rearrangements in pediatric patients with PTC $[18,19]$.

Sorafenib improves progression free survival in patients with well-differentiated thyroid carcinoma [20, 21]. Previous studies of sorafenib in pediatric patients with PTC 
have reported marked reduction in pulmonary metastases $[22,23]$. Rash, hand-foot skin reaction, gastrointestinal symptoms, fatigue, and hypertension are commonly observed adverse effects of sorafenib [13]. Our patient showed clinical and radiographic improvement after administration of sorafenib and the adverse effects were mild and tolerable. Furthermore, sorafenib can be administered in an outpatient setting and is easily managed. In fact, the patient can take oral medication by collaborating with his family. However, thyroid remnant and metastases remain as yet and sorafenib is expensive drug. We would conduct RAI therapy if the patient were to take care of himself. The Children's Oncology Group recently described a phase 2 study of sorafenib in refractory solid tumors; unfortunately, no patients with PTC were enrolled in this study [24]. Furthermore, growth plate abnormalities were observed in young animals with tyrosine kinase inhibitors including sorafenib, and growth plate widening were reported in pediatric cancer patients undergoing phase 1 studies of tyrosine kinase inhibitors [25]. Unfortunately, we did not evaluate his growth plate before the treatment, but he showed no unequivocal growth plate widening after over 24 months of receiving sorafenib. Further studies are required to evaluate the effectiveness and longterm safety of this molecular target inhibitor in pediatric patients with PTC.

In conclusion, we report the case of a PTC with diffuse pulmonary metastases in a pediatric patient with ASD. We inevitably used sorafenib as an alternative to standard therapy because of the patient's specific circumstances. Individualized strategies for pediatric cancer patients with ASD are needed.

\section{Abbreviations \\ ASD: Autism spectrum disorder; BID: Two divided doses per day; CTCAE: Common Terminology criteria for Adverse Events; PTC: Papillary thyroid carcinoma; RAl: Radioactive iodine; SpO2: Percutaneous oxygen saturation; Tg: Thyroglobulin}

\section{Acknowledgements}

The authors thank Dr. Yoshiyuki Usui (Department of Brest and Thyroid Surgery, Okayama Medical Center, Okayama, Japan) for clinical advice. They also wish to thank the staff of the Department of Pathology, Okayama University Hospital for assessment of pathologic features.

We thank Edanz (https://www.edanzediting.co.jp) for English writing assistance.

\section{Funding}

This study was supported in part by a Grant-in-Aid for Cancer Research and a grant for Clinical Cancer Research and Research on Children and Families from the Ministry of Health, Labor and Welfare of Japan. The funding body had no role in the design of the study and collection, analysis, and interpretation of data and in writing this manuscript.

\section{Availability of data and materials}

The datasets used and/or analyzed during the current study are available from the corresponding author on reasonable request.

\section{Authors' contributions}

YH drafted the initial manuscript, reviewed and revised the manuscript. TM, $\mathrm{TO}$ and TN reviewed and revised the manuscript and were involved in the surgical management of the patient. HI, KK, KW and HT reviewed and revised the manuscript and were involved in the case management, conceptualized the case report. $Y T$ and $A O$ reviewed and revised the manuscript and were involved in the evaluation of the patient's mental retardation. AS concepted and designed the case report, carried out the analyses and revised the manuscript. All authors approved the final manuscript as submitted and agree to be accountable for all aspects of the work.

\section{Ethics approval and consent to participate}

All procedures performed in this study were in accordance with the ethical standard of Okayama University Hospital and with the 1964 Helsinki declaration and its later amendments. The genetic analysis was approved by the Ethics Committee of Okayama University Hospital (approval no. Ge-305). Written informed consent was obtained from patient's parents for the analysis.

\section{Consent for publication}

Written informed consent was obtained from the patient's parents for treatment and publication of this report and any accompanying images.

\section{Competing interests}

The authors declare that they have no competing interests.

\section{Publisher's Note}

Springer Nature remains neutral with regard to jurisdictional claims in published maps and institutional affiliations.

\section{Author details}

${ }^{1}$ Department of Pediatrics, Okayama University Hospital, 2-5-1 Shikata-cho, Kita-ku, Okayama 700-8558, Japan. ${ }^{2}$ Department of General Thoracic Surgery and Breast and Endocrine Surgery, Okayama University Hospital, 2-5-1 Shikata-cho, Kita-ku, Okayama 700-8558, Japan. ${ }^{3}$ Department of Pediatric Surgery, Okayama University Hospital, 2-5-1 Shikata-cho, Kita-ku, Okayama 700-8558, Japan. ${ }^{4}$ Department of Pediatrics, Okayama University Graduate School of Medicine, Dentistry and Pharmaceutical Sciences, 2-5-1

Shikata-cho, Kita-ku, Okayama 700-8558, Japan.

Received: 14 March 2017 Accepted: 13 November 2017

Published online: 21 November 2017

\section{References}

1. Howlader N, Noone AM, Krapcho M, Miller D, Bishop K, Altekruse SF, Kosary CL, Yu M, Ruhl J, Tatalovich Z, Mariotto A, Lewis DR, Chen HS, Feuer EJ, Cronin KA (eds). SEER Cancer Statistics Review, 1975-2014, National Cancer Institute. Bethesda, MD, Available at www.seer.cancer.gov/csr/1975_2014/ Accessed July 10, 2017.

2. Chaukar DA, Rangarajan V, Nair N, Dcruz AK, Nadkarni MS, Pai PS, et al. Pediatric thyroid cancer. J Surg Oncol. 2005;92:130-3.

3. Vaisman F, Corbo R, Vaisman M. Thyroid carcinoma in children and adolescentssystematic review of the literature. J Thyroid Res. 2011;2011:845362.

4. Jarzab B, Handkiewicz Junak D, Wloch J, Kalemba B, Roskosz J, Kukulska A, et al. Multivariate analysis of prognostic factors for differentiated thyroid carcinoma in children. Eur J Nucl Med. 2000:27:833-41.

5. Rivkees S a, Mazzaferri EL, Verburg F a, Reiners C, Luster M, Breuer CK, et al. The treatment of differentiated thyroid cancer in children: emphasis on surgical approach and radioactive iodine therapy. Endocr Rev. 2011;32:798-826.

6. Woyach $\mathrm{J}$ a, Shah MH. New therapeutic advances in the management of progressive thyroid cancer. Endocr Relat Cancer. 2009;16:715-31.

7. Murphy D a, Makonnen S, Lassoued W, Feldman MD, Carter C, Lee WMF. Inhibition of tumor endothelial ERK activation, angiogenesis, and tumor growth by sorafenib (BAY43-9006). Am J Pathol. 2006;169:1875-85.

8. Brose MS, Nutting CM, Jarzab B, Elisei R, Siena S, Bastholt L, et al. Sorafenib in radioactive iodine-refractory, locally advanced or metastatic differentiated thyroid cancer: a randomised, double-blind, phase 3 trial. Lancet. 2014;384:319-28.

9. American Psychiatric Association. Diagnostic and statistical manual of mental disorders. 5th ed. Washington, DC: American Psychiatric Association; 2013.

10. Christensen DL, Baio J, Braun KVN, Bilder D, Charles J, Constantino JN, et al. Prevalence and characteristics of autism Spectrum disorder among children aged 8 years - autism and developmental disabilities monitoring network, 11 sites, United States, 2012. Morb Mortal Wkly report Surveill Summ. 2016;65:1-23. 
11. Johnson NL, Rodriguez D. Children with autism spectrum disorder at a pediatric hospital: a systematic review of the literature. Pediatr Nurs. 2013;39:131-41.

12. Widemann BC, Kim A, Fox E, Baruchel S, Adamson PC, Ingle AM, et al. A phase I trial and pharmacokinetic study of sorafenib in children with refractory solid tumors or leukemias: a Children's oncology group phase I consortium report. Clin Cancer Res. 2012;18:6011-22.

13. Brose MS, Frenette CT, Keefe SM, Stein SM. Management of Sorafenib-Related Adverse Events: a Clinician's perspective. Semin Oncol Elsevier. 2014;41:S1-16.

14. National Cancer Institute. Common Terminology Criteria for Adverse Events v.4.0 (CTCAE). Available at: ctep.cancer.gov/protocoldevelopment/ electronic_applications/ctc.htm Accessed July 10, 2017.

15. Edge SB, Compton CC. The American joint committee on cancer: the 7th edition of the AJCC cancer staging manual and the future of TNM. Ann Surg Oncol. 2010:17:1471-4.

16. Francis GL, Waguespack SG, Bauer AJ, Angelos P, Benvenga S, Cerutti JM, et al. Management guidelines for children with thyroid nodules and differentiated thyroid cancer. Thyroid. 2015;25:716-59.

17. Yu X-M, Schneider DF, Leverson G, Chen H. Sippel RS 2013 follicular variant of papillary thyroid carcinoma is a unique clinical entity: a population-based study of 10,740 cases. Thyroid. 2013;23:1263-8.

18. Ballester LY, Sarabia SF, Sayeed H, Patel N, Baalwa J, Athanassaki I, et al. Integrating molecular testing in the diagnosis and Management of Children with thyroid lesions. Pediatr Dev Pathol. 2015;19:94-100.

19. Picarsic JL, Buryk MA, Ozolek J, Ranganathan S, Monaco SE, Simons JP, et al. Molecular characterization of sporadic pediatric thyroid carcinoma with the DNA/RNA ThyroSeq v2 next-generation sequencing assay. Pediatr Dev Pathol. 2016;19:115-22.

20. Gupta-Abramson V, Troxel AB, Nellore A, Puttaswamy K, Redlinger M, Ransone $K$, et al. Phase II trial of sorafenib in advanced thyroid cancer. J Clin Oncol. 2008:26:4714-9.

21. Kloos RT, Ringel MD, Knopp MV, Hall NC, King M, Stevens R, et al. Phase II trial of sorafenib in metastatic thyroid cancer. J Clin Oncol. 2009;27:1675-84.

22. Waguespack SG, Sherman SI, Williams MD, Clayman GL, Herzog CE. The successful use of sorafenib to treat pediatric papillary thyroid carcinoma. Thyroid. 2009;19:407-12.

23. Iyer $P$, Mayer JLR, Ewig JM. Response to Sorafenib in a pediatric patient with papillary thyroid carcinoma with diffuse nodular pulmonary disease requiring mechanical ventilation. Thyroid. 2014;24:169-74.

24. Kim A, Widemann BC, Krailo M, Jayaprakash N, Fox E, Weigel B, et al. Phase 2 trial of sorafenib in children and young adults with refractory solid tumors: a report from the Children's oncology group. Pediatr Blood Cancer. 2015;62:1562-6.

25. Voss SD, Glade-Bender J, Spunt SL, DuBois SG, Widemann BC, Park JR, et al. Growth plate abnormalities in pediatric cancer patients undergoing phase 1 anti-angiogenic therapy: a report from the children's oncology group phase I consortium. Pediatr Blood Cancer. 2015:62:45-51.

\section{Submit your next manuscript to BioMed Central and we will help you at every step:}

- We accept pre-submission inquiries

- Our selector tool helps you to find the most relevant journal

- We provide round the clock customer support

- Convenient online submission

- Thorough peer review

- Inclusion in PubMed and all major indexing services

- Maximum visibility for your research

Submit your manuscript at www.biomedcentral.com/submit 